\title{
Vibration Diagnosis and Treatment for a Scrubber System Connected to a Reciprocating Compressor
}

\author{
Shuangshuang Li $\mathbb{D},{ }^{1}$ Guicheng Yu $\mathbb{D},{ }^{2}$ Ding Tang $\mathbb{D}^{2},{ }^{2}$ Ming Li $\mathbb{D},{ }^{2}$ and Huaming Han $\mathbb{D}^{3}$ \\ ${ }^{1}$ School of Mechanical Engineering, Xihua University, Chengdu 610039, China \\ ${ }^{2}$ Gas Storage Management Department of PetroChina Southwest Oil and Gasfield Company, Chongqing 401147, China \\ ${ }^{3}$ Chongqing Gas District of PetroChina Southwest Oil and Gasfield Company, Chongqing 400021, China
}

Correspondence should be addressed to Shuangshuang Li; 15882068051@163.com

Received 19 October 2020; Revised 2 November 2020; Accepted 4 November 2020; Published 24 November 2020

Academic Editor: Aijun Yin

Copyright (C) 2020 Shuangshuang Li et al. This is an open access article distributed under the Creative Commons Attribution License, which permits unrestricted use, distribution, and reproduction in any medium, provided the original work is properly cited.

\begin{abstract}
Severe vibration was observed at a scrubber system connected to a reciprocating compressor during commissioning stage. Field measurements including vibration, pressure pulsation, and modal experiment were conducted to determine the causes of vibration, which showed that the excessive vibration was caused by pressure pulsation-induced mechanical resonance. Vibration reduction treatment for mechanical resonance avoidance via the installation of support on scrubber was proposed and then validated by resonance analysis and one-way fluid structure interaction (FSI) analysis. Resonance analysis showed both the dominant frequencies of pressure pulsation and rotational frequencies of compressor were beyond resonance regions, and FSI analysis indicated that the vibration levels of the scrubber system at its design conditions were within the allowable limit. Installation of two braces with a band clamp on the scrubber was implemented. The effectiveness of the treatment was verified by comparison of measured data before and after scrubber modification; the peak amplitudes occurring at the dominant excitation frequencies in both vibration and pulsation spectra declined greatly after modification, which guaranteed the longterm stable operation of the scrubber.
\end{abstract}

\section{Introduction}

Reciprocating compressors are widely used to boost natural gas pressure to be required because of their flexibility in capacity and pressure range in natural gas storage industry. Since the high-pressure gas discharged from the compression cylinder of a compressor always contains lube oils, a scrubber must be applied on the outlet of the compressor for removal of the lube oils to ensure gas quality before entering the underground storage facilities. Gas pressure pulsations produced by the reciprocating action of the piston could inevitably be transmitted into the pipelines and equipment attached to a reciprocating compressor; no problem occurs unless they coincide with a particular mechanical or acoustic frequency of the system. The pressure pulsations can then be greatly amplified and excite the pipelines and/or equipment, which may result in high vibration. Excessive vibration can lead to many practical problems, such as pipeline fatigue failure, equipment damage, instrument distortion, power consumption, and energy loss. Pipelines and equipment carrying high-pressure and high-speed gas need a high level of reliability and stability.

The vibration of pipelines and equipment connected to the reciprocating compressor is a typical flow-induced vibration. Relevant studies show that vibration is generally induced by poor dynamic balance of structure, poor kinematical design, mechanical resonance, and large pressure pulsations. Researches concerning such vibration have been focusing on three different areas: vibration theory and analysis, vibration diagnosis and identification techniques, and vibration control methods. Vibration theory and analysis mainly include establishment of a vibration model, analytical and numerical solutions of the vibration model $[1,2]$, modal analysis for avoidance of resonance, vibration analysis and related experimental research [3], fluid-structure interaction (FSI) vibration study $[4,5]$, vibration dynamic response of 
system, acoustic and pulsation analysis using acoustic wave theory, transfer matrix method, and finite element methods $[6,7]$. Numerous vibration analysis techniques are employed to predict the vibration level of system during the design phase and to identify the source of high vibration in the operation phase, which mainly focus on field measurement methods, test instrumentation, signal processing, and frequency spectrum analysis $[8,9]$. Vibration control methods are aimed at proposing a proper design and/or modification to reduce the mechanical vibration and pressure pulsation to a minimum. Vibration can be controlled by increasing pipe size, increasing buffer tank, shorting pipeline length, adding support, installing orifice, and so on [10-13]. Recent vibration reduction studies mainly focus on natural frequency adjustment and pressure pulsation control [14-16].

These studies lay the foundation for diagnosis, identification, analysis, and mitigation of flow-induced vibration in a reciprocating compressor systems. This paper is devoted to determine the main causes of high vibration encountered by a scrubber system through field vibration measurement, pulsation measurement, and modal experiment and put forward effective vibration reduction treatment via resonance analysis and one-way FSI vibration analysis.

\section{Vibration Diagnosis and Cause Analysis}

One underground natural gas storage station has employed eight reciprocating compressors with a rated power of $4000 \mathrm{~kW}$ and a design processing capacity of $166 \times 10^{4}$ $\mathrm{Nm}^{3} / \mathrm{d}$ each to boost natural gas pressure. Each reciprocating compressor is equipped with a scrubber in size $\Phi 610 \mathrm{~mm} \times$ $2921 \mathrm{~mm}$ to remove lube oil to $0.1 \mu \mathrm{m}$ from natural gas to ensure its quality and protect gas storage facilities. During the commissioning of the reciprocating compressor, one scrubber system (see Figure 1) encountered excessive vibration as high as $40 \mathrm{~mm} / \mathrm{s}$ RMS, which was considered to be dangerous and should be controlled to values less than $18 \mathrm{~mm} / \mathrm{s}$ to ensure the safety and reliability of the scrubber system [17]. Field measurements are conducted to investigate the factors resulting in such problem, as presented in Figure 2. Measuring parameters include vibration, pressure pulsation, and modal. The measurement sensors employed for field measurements comprise an accelerometer for vibration test, a pressure transmitter for pressure test, and an impact hammer for modal test, in which main specifications are given in Table 1.

2.1. Vibration Measurements and Analysis. Vibration measurements were performed to investigate the causes of vibration. The operating parameters of the reciprocating compressor are listed in Table 2. Three vibration measuring points V1, V2, and V3 are located at the scrubber inlet pipeline, the top of the scrubber, and the scrubber outlet pipeline, respectively; each measuring point contains $\mathrm{H}$ (horizontal), $\mathrm{V}$ (vertical), and A (axial) directions, as shown in Figure 1. Vibration measurement results including vibration displacement, velocity, and acceleration measured by an accelerometer are listed in Table 3. Generally, the velocity method is used to determine the vibration level for low-frequency

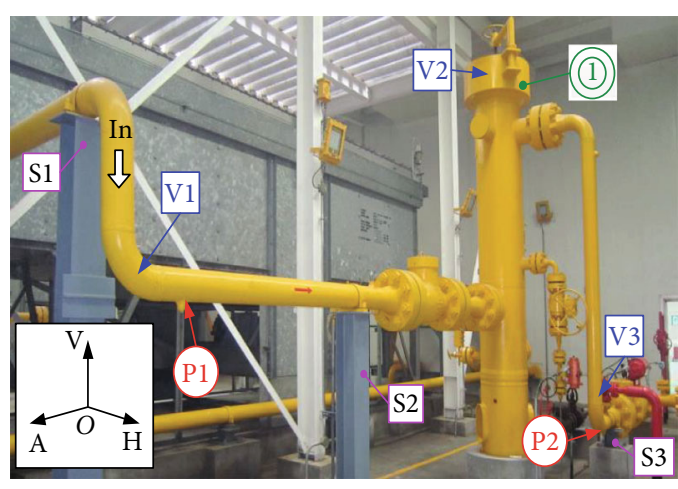

Figure 1: Scrubber system connected to a reciprocating compressor.

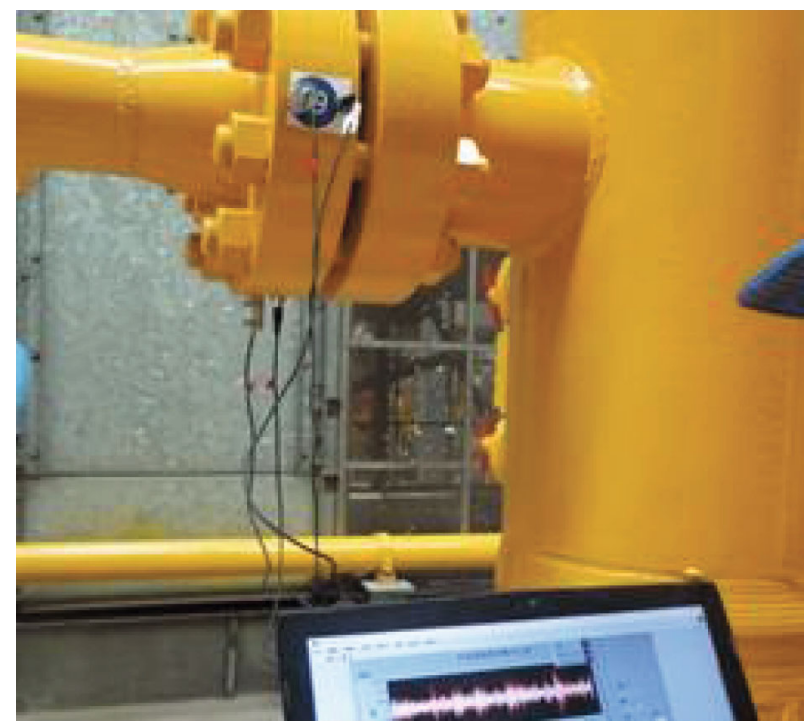

Figure 2: Field measurements for the scrubber system.

steady-state vibration. Table 3 reveals that the maximum velocity is observed at the top of the scrubber, especially in the A direction, and the velocity values measured at measuring point $\mathrm{V} 2$ in the $\mathrm{H}$ and $\mathrm{A}$ directions are greater than the allowable velocity limits $(18 \mathrm{~mm} / \mathrm{s})$, which indicates that the scrubber stiffness in the $A$ direction is weaker than that in the $\mathrm{H}$ and $\mathrm{V}$ directions.

Vibration spectrum analysis was applied to identify the frequency contents of the vibration signals [18]. The vibration frequency spectra measured at points V1, V2, and V3 in the A direction are displayed in Figure 3. The problematic frequency components can be seen straight. The spectrum measured at point V1 in the A direction exhibits mainly two dominant frequency components of $16.56 \mathrm{~Hz}$ and $32.39 \mathrm{~Hz}$, which are related to the reciprocating compressor rotational frequency and its second harmonics calculated by Equation (1). This revealed that the main source of vibration excitation at the scrubber inlet pipeline was the pressure pulsation caused by the intermittent suction/discharge flow of the reciprocating compressor. The spectrum measured at $\mathrm{V} 2$ in the A direction shows mainly two dominant frequency components of $5.9 \mathrm{~Hz}$ and $16.56 \mathrm{~Hz}$; the vibration peak at 
TABLE 1: Measurement sensors and the main specifications.

\begin{tabular}{|c|c|c|c|}
\hline Sensor & Measuring parameter & Type & Technical specifications \\
\hline Accelerometer & Vibration & PCB 608A11 & $\begin{array}{l}\text { Range: } 0.5 \mathrm{~Hz} \text { to } 10 \mathrm{kHz} \\
\text { Sensitivity }( \pm 15 \%): 100 \mathrm{mV} / \mathrm{g} \\
\text { Measurement range: } \pm 50 \mathrm{~g} \\
\text { Broadband resolution: } 350 \mu \mathrm{g}\end{array}$ \\
\hline Pressure transmitter & Pressure & Wotian PCM 301 & $\begin{array}{l}\text { Range: } 0 \sim 30 \mathrm{MPa} \\
\text { Accuracy: } \pm 0.5 \% \\
\text { Response time: } \leq 1 \mathrm{~ms} \\
\text { Shock: } 100 \mathrm{~g}\end{array}$ \\
\hline Impact hammer & Modal & PCB 086D20 & $\begin{array}{c}\text { Range: } \pm 22,240 \mathrm{~N} \mathrm{pk} \\
\text { Sensitivity ( } \pm 15 \%): 0.23 \mathrm{mV} / \mathrm{N} \\
\text { Resonant frequency: } 12 \mathrm{kHz} \\
\text { Nonlinearity: } 1 \%\end{array}$ \\
\hline
\end{tabular}

TABLE 2: The main operating parameters of the reciprocating compressor.

\begin{tabular}{lcccc}
\hline $\begin{array}{l}\text { Rotational } \\
\text { speed }(\mathrm{rpm})\end{array}$ & $\begin{array}{c}\text { Processing } \\
\text { capacity }\left(\mathrm{Nm}^{3} / \mathrm{d}\right)\end{array}$ & $\begin{array}{c}\text { Inlet } \\
\text { pressure } \\
(\mathrm{MPa})\end{array}$ & $\begin{array}{c}\text { Outlet pressure } \\
(\mathrm{MPa}) \\
\text { stage }\end{array}$ & $\begin{array}{c}\text { Second } \\
\text { stage }\end{array}$ \\
\hline 994 & $149.2 \times 10^{4}$ & 7.61 & 13.62 & 24.41 \\
\hline
\end{tabular}

TABLE 3: Vibration measurement results at the three points V1, V2, and V3.

\begin{tabular}{lcccc}
\hline Point & Direction & $\begin{array}{c}\text { Displacement } \\
(\mu \mathrm{m} \text { RMS })\end{array}$ & $\begin{array}{c}\text { Velocity } \\
(\mathrm{mm} / \mathrm{s} \text { RMS })\end{array}$ & $\begin{array}{c}\text { Acceleration } \\
\left(\mathrm{m} / \mathrm{s}^{2} \mathrm{RMS}\right)\end{array}$ \\
\hline \multirow{3}{*}{ V1 } & $\mathrm{H}$ & 196.1 & 15.33 & 1.85 \\
& $\mathrm{~V}$ & 125.65 & 11.55 & 1.63 \\
& $\mathrm{~A}$ & 105.49 & 10.78 & 1.31 \\
$\mathrm{~V} 2$ & $\mathrm{H}$ & 215.8 & 18.6 & 1.91 \\
& $\mathrm{~V}$ & 83.29 & 9.45 & 1.39 \\
& $\mathrm{~A}$ & 271.7 & 25.76 & 2.04 \\
$\mathrm{~V} 3$ & $\mathrm{H}$ & 49.03 & 4.41 & 0.89 \\
& $\mathrm{~V}$ & 57.97 & 5.83 & 0.94 \\
& $\mathrm{~A}$ & 71.32 & 8.56 & 1.12 \\
\hline
\end{tabular}

$5.9 \mathrm{~Hz}$ contributes to about $70 \%$ of the total vibration. Similarly, the two dominant frequencies of $5.9 \mathrm{~Hz}$ and $16.56 \mathrm{~Hz}$ are observed at the point V3 in the A direction. It is known that the pipelines and equipment connected to the reciprocating compressor vibrate inevitably at the rotational frequency and harmonics of the compressor. Hence, the problematic frequency of $5.9 \mathrm{~Hz}$ observed at the top of the scrubber was usually related to the scrubber structure and/or flow-induced vibration (FIV).

$$
f_{\text {ex }}=\frac{N}{60} k i
$$

where $f_{\text {ex }}$ is the compressor rotational frequency $(\mathrm{Hz}) ; N$ is the compressor rotational speed (rpm), for single-action piston $k=1$ or double-action piston $k=2$; and $i$ is the harmonic order of frequency.

\subsection{Acoustic and Pulsation Analysis}

2.2.1. Acoustic Analysis. The pressure pulsations of fluid are referred to as acoustical, because they travel through a system at the speed of sound of the gas. Pressure pulsations are generally too weak to cause any problem; however, they can be strongly amplified and result in high vibration due to acoustic resonance when a particular excitation frequency matches the acoustic frequency. Acoustic analysis was carried out to find out the acoustic frequencies of system using the transfer matrix method. In this method, the structural system is divided into several elements such as a pipe, a volume, and a resistance [19]. Each element has a transfer matrix $[M]$. Ignoring damping effects, the $2 \times 2$ transfer matrix is then formulated by multiplying all the transfer matrices to relate the pressure pulsation $p$ and the flow pulsation $u$ between the inlet and outlet of system, which can be written as [20]

$$
\left[\begin{array}{c}
p_{\text {out }} \\
u_{\text {out }}
\end{array}\right]=\left[M_{n}\right]\left[M_{n-1}\right] \cdots\left[M_{2}\right]\left[M_{1}\right]\left[\begin{array}{c}
p_{\text {in }} \\
u_{\text {in }}
\end{array}\right] .
$$

The subscripts "in" and "out" represent the conditions at the inlet and outlet of the system, respectively. As presented in Figure 1, the scrubber system is mainly composed of three elements: the inlet pipeline, scrubber itself, and outlet pipeline. Therefore, the mathematical model for the scrubber system can be considered to a "P-V-P" (pipe-volume-pipe) acoustic system, as shown in Figure 4. The transfer matrices of the inlet pipeline, scrubber itself, and outlet pipeline are given by Equations (3), (4), and (5), respectively. So the matrix equation of an acoustic model for the scrubber system can be expressed by Equations (6).

$$
\left[M_{1}\right]=\left[\begin{array}{cc}
\cos \frac{\omega}{a} L_{1} & -\rho_{0} a \sin \frac{\omega}{a} L_{1} \\
\frac{1}{\rho_{0} a} \sin \frac{\omega}{a} L_{1} & \cos \frac{\omega}{a} L_{1}
\end{array}\right],
$$

$$
\left[M_{2}\right]=\left[\begin{array}{cc}
1 & 0 \\
\frac{V \omega}{S_{2} \rho_{0} a^{2}} & \frac{S_{1}}{S_{2}}
\end{array}\right],
$$




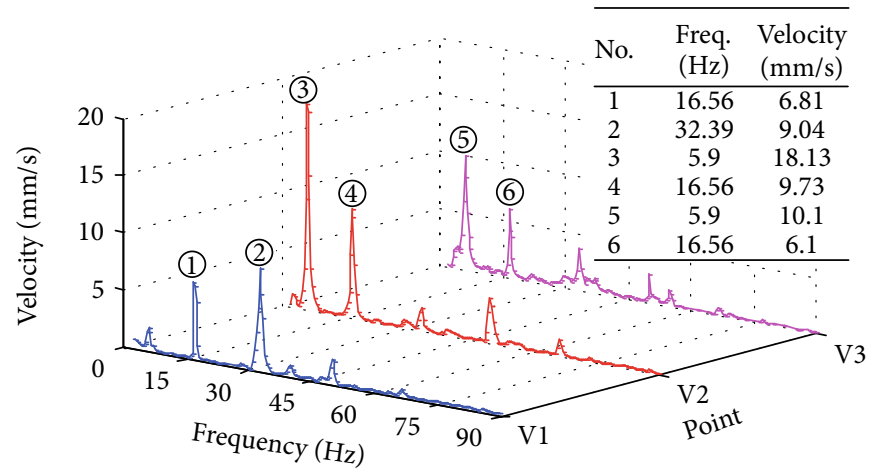

FIgURE 3: Vibration spectrum comparison of the three points in the A (axial) direction.

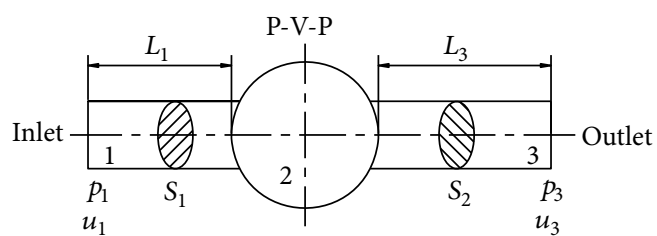

Figure 4: Acoustic mathematical model of the scrubber system.

$$
\begin{aligned}
& {\left[M_{3}\right]=\left[\begin{array}{cc}
\cos \frac{\omega}{a} L_{2} & -\rho_{0} a \sin \frac{\omega}{a} L_{2} \\
\frac{1}{\rho_{0} a} \sin \frac{\omega}{a} L_{2} & \cos \frac{\omega}{a} L_{2}
\end{array}\right],} \\
& {\left[\begin{array}{l}
p_{3} \\
u_{3}
\end{array}\right]=\left[M_{3}\right]\left[M_{2}\right]\left[M_{1}\right]\left[\begin{array}{l}
p_{1} \\
u_{1}
\end{array}\right],}
\end{aligned}
$$

where $\omega$ is the angular velocity $(\mathrm{rad} / \mathrm{s}), L$ is the effective length of the pipeline $(\mathrm{m}), a$ is the sound speed of gas $(\mathrm{m} / \mathrm{s}), \rho$ is the density of gas $\left(\mathrm{kg} / \mathrm{m}^{3}\right), S$ is the crosssectional area inside the pipeline $\left(\mathrm{m}^{2}\right), V$ is the volume of volume element $\left(\mathrm{m}^{3}\right)$, and the subscripts 1,2 , and 3 represent the number of each element.

The acoustic frequencies can be determined by solving Equation (6) in consideration of boundary conditions. The pipeline connected to a large volume can be regarded as an open end, if not, a closed end. For an open end, the boundary conditions are that the pressure pulsation $p$ is zero but flow pulsation $u$ is not zero; for a closed end, the flow pulsation $u$ is zero but pressure pulsation $p$ is not zero. The pulsation can be set to 1 when it is not zero, which will not affect the results of acoustic frequencies. So the boundary conditions of the scrubber system are

$$
\begin{cases}p_{3}=1, & u_{3}=0 \\ p_{1}=1, & u_{1}=0\end{cases}
$$

Using these boundary conditions in Equation (7), Equation (6) can be derived as
TABLE 4: The key structure parameters of the scrubber system.

\begin{tabular}{lccccc}
\hline Parameter & $\mathrm{L} 1(\mathrm{~m})$ & $\mathrm{L} 2(\mathrm{~m})$ & $\mathrm{S} 1\left(\mathrm{~m}^{2}\right)$ & $\mathrm{S} 2\left(\mathrm{~m}^{2}\right)$ & $V\left(\mathrm{~m}^{3}\right)$ \\
\hline Value & 11 & 9 & 0.528 & 0.528 & 0.0154
\end{tabular}

TABLE 5: Physical properties of the natural gas in the scrubber system.

\begin{tabular}{lcc}
\hline Property & Symbol & Value \\
\hline Ratio of specific heats & $k_{\mathrm{v}}$ & 1.29 \\
Relative density & $r_{\rho}$ & 0.588 \\
Gas constant $(\mathrm{J} /(\mathrm{kg} \cdot \mathrm{K}))$ & $R_{\mathrm{g}}$ & 488.06 \\
Absolute pressure $(\mathrm{MPa})$ & $p$ & 24.41 \\
Absolute temperature $(\mathrm{K})$ & $T$ & 311.15 \\
Compressibility factor & $Z$ & 0.838 \\
Sound speed $(\mathrm{m} / \mathrm{s})$ & $a$ & 431.4 \\
\hline
\end{tabular}

TABLE 6: The first four acoustic frequencies of the scrubber system.

\begin{tabular}{lcccc}
\hline Acoustic frequency & First & Second & Third & Fourth \\
\hline$f_{\mathrm{ac}}(\mathrm{Hz})$ & 10.42 & 13.41 & 29.81 & 36.32 \\
\hline
\end{tabular}

$$
\begin{aligned}
\sin \frac{\omega}{a} L_{2} \cos \frac{\omega}{a} L_{1} & +\frac{V \omega}{S_{2} a} \cos \frac{\omega}{a} L_{2} \cos \frac{\omega}{a} L_{1} \\
& +\cos \frac{\omega}{a} L_{2} \sin \frac{\omega}{a} L_{1}=0, \\
f_{\mathrm{ac}} & =\frac{\omega}{2 \pi} .
\end{aligned}
$$

The acoustic frequencies $f_{\text {ac }}$ of the scrubber system not only depend on its structure parameters but also on the fluid parameters inside the scrubber, such as density and sound speed of fluid. The key structure parameters of the scrubber system and physical properties of the natural gas in the scrubber system are given in Tables 4 and 5, respectively. Using these data, the first four acoustic frequencies of the scrubber system were calculated by solving Equation (8) and Equation (9), in which results are listed in Table 6. As discussed above, the main excitation frequencies of vibration are $5.9 \mathrm{~Hz}$ and $16.56 \mathrm{~Hz}$ (the rotational frequency) and in its 


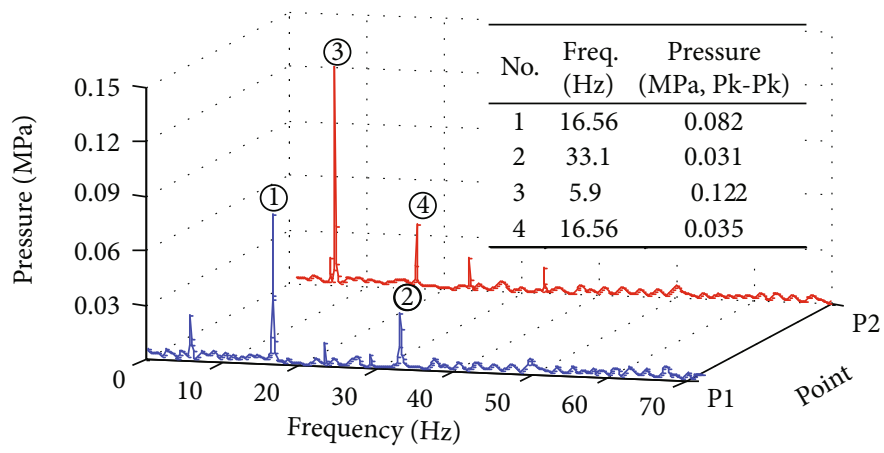

FIGURe 5: Pressure spectrum comparison of points P1 and P2.

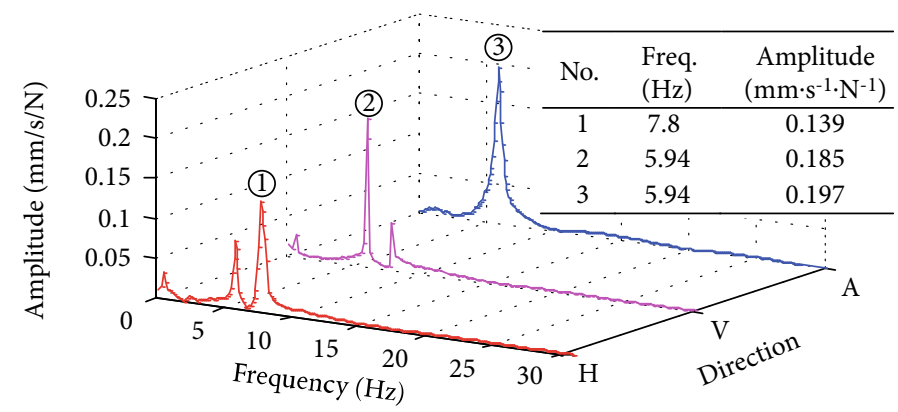

FIGURE 6: Impact response spectrum obtained at impact point (1) by modal experiment.

harmonics, it is obvious that the acoustic frequencies of the scrubber system are far away from them. It can be concluded that the acoustic frequencies of the scrubber system were not excited by the main excitation frequencies; there was no acoustic resonance in the scrubber system.

2.2.2. Pulsation Analysis. Even for steady flow conditions, pressure pulsation is an important source of energy responsible for scrubber vibration. Pressure pulsation has several characteristic frequencies, which normally results in lowamplitude vibration, and no problem occurs unless these pulsations coincide with the mechanical and/or acoustical resonance frequency of a system. Pulsation measurements were performed upstream and downstream of the scrubber using a pressure transmitter to find the dominant excitation frequency components. Two pressure pulsation measuring points P1 and P2 are shown in Figure 1. The frequency components and magnitude of the pressure pulsation were analysed to determine its characteristics and its potential effect, in which results are represented in Figure 5. It can be seen that the resulting pressure pulsation is a low-frequency pulsation; the pulsation at point P1 mainly contains several harmonics of the rotational frequency of $16.56 \mathrm{~Hz}$; however, the pulsation at point $\mathrm{P} 2$ is strongest at $5.9 \mathrm{~Hz}$; spikes at the harmonics of $16.56 \mathrm{~Hz}$ exist as well. As the dominant frequency of $5.9 \mathrm{~Hz}$ was observed downstream of the scrubber but not observed upstream of the scrubber, it can be concluded that the dominant excitation frequency occurred at $5.9 \mathrm{~Hz}$.

2.3. Modal Analysis. Modal experiment was conducted at the impact point (1) (see Figure 1) to acquire the MNFs (mechanical natural frequencies) of the scrubber system. From

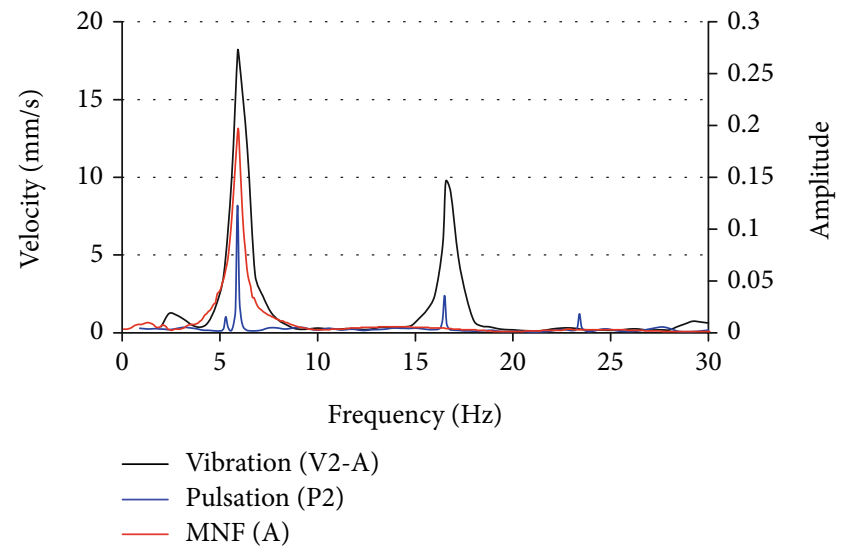

FIGURE 7: The spectrum overlay of vibration, pulsation, and MNF.

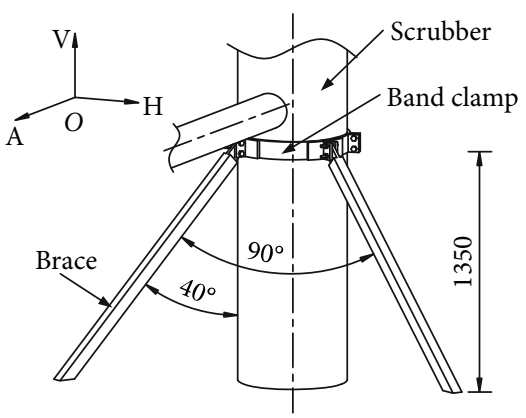

FIGURE 8: The scrubber supported by two braces with a band clamp. 


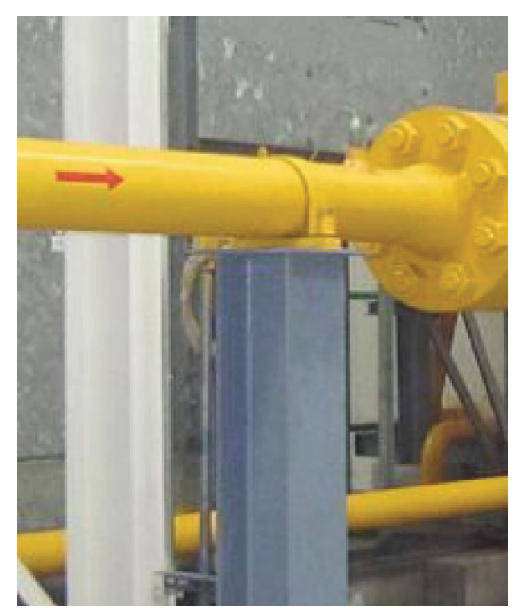

(a)

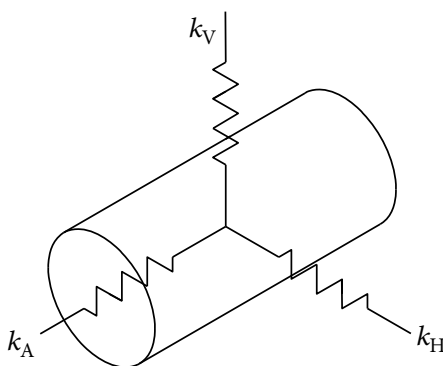

(b)

FIGURE 9: Pipe support: (a) common support; (b) support simplified model.

TABLE 7: The boundary conditions applied in the simulation model of the original scrubber system.

\begin{tabular}{lc}
\hline Location & Boundary conditions \\
\hline S1 & $k_{\mathrm{H}}=3.80 E+03 \mathrm{~N} / \mathrm{mm}, k_{\mathrm{V}}=7.60 E+05 \mathrm{~N} / \mathrm{mm}, k_{\mathrm{A}}=2.67 E+04 \mathrm{~N} / \mathrm{mm}$ \\
$\mathrm{S} 2$ & $k_{\mathrm{H}}=5.87 E+04 \mathrm{~N} / \mathrm{mm}, k_{\mathrm{V}}=9.88 E+05 \mathrm{~N} / \mathrm{mm}, k_{\mathrm{A}}=8.34 E+03 \mathrm{~N} / \mathrm{mm}$ \\
$\mathrm{S} 3$ & $k_{\mathrm{H}}=2.17 E+06 \mathrm{~N} / \mathrm{mm}, k_{\mathrm{V}}=3.29 E+06 \mathrm{~N} / \mathrm{mm}, k_{\mathrm{A}}=3.09 E+05 \mathrm{~N} / \mathrm{mm}$ \\
\hline
\end{tabular}

Figure 6, two fundamental frequencies of $5.94 \mathrm{~Hz}$ and $7.8 \mathrm{~Hz}$ are found in the three directions; the peak amplitude in the A direction is greater compared to the other two directions, which indicates that the scrubber is more likely to vibrate in the A direction.

Meanwhile, the relationships among the vibration, pressure pulsation, and MNFs of the scrubber system can be compared to reveal potential causes of vibration. According to the spectrum overlay shown in Figure 7, the dominant frequency of pressure pulsation at $5.9 \mathrm{~Hz}$ is very close to the first MNF of the scrubber system of $5.94 \mathrm{~Hz}$; the highest vibration occurs at $5.9 \mathrm{~Hz}$, so it can be concluded that the main cause of the excessive vibration was pressure pulsation-induced mechanical resonance.

\section{Vibration Reduction Treatment and Analysis}

3.1. Vibration Reduction Treatment. The motion equation of forced vibration of a structure system is given by Equation (10). In practice, it is useful to add mass, increase damping, add stiffness, and reduce exciting force to minimize the vibration response of a structure system.

$$
M\{\ddot{x}(t)\}+C\{\dot{x}(t)\}+K\{x(t)\}=\{F(t)\},
$$

where $M$ is the mass matrix, $C$ is the damping matrix, $K$ is the stiffness matrix, $\{F(t)\}$ is the exciting force vector, and $\{x($ $t)\}$ is the vibration displacement vector.

The highest vibration level at $5.9 \mathrm{~Hz}$ was due to resonance, so it is necessary to separate the MNFs of the scrubber system from the dominant frequency of pulsation as a countermeasure against vibration. Resonance avoidance solutions

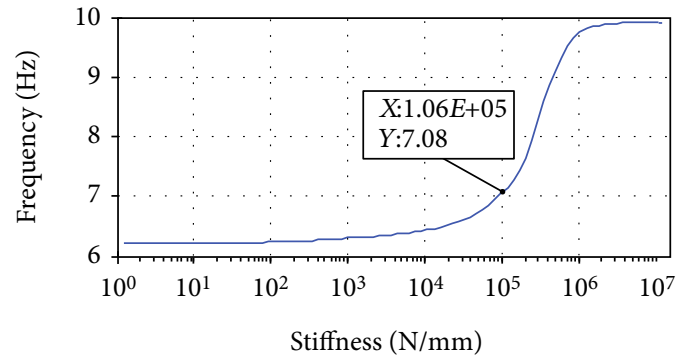

Figure 10: The effect of the axial stiffness of the brace on the first MNF of the modified model.

were needed to eliminate such vibration problem, such as adjusting MNFs by adding support and change in operation conditions to shift pulsation frequency. As the scrubber must have a wide range of operating conditions to meet the requirements of reciprocating compressor, changing the MNFs of the scrubber system was more effective than changing the operation conditions to control vibration. As discussed above, the vibration of the scrubber system is lowfrequency vibration; the vibration response of the system can be said to be stiffness dominated. A practical method of changing the MNFs of the scrubber system may be installation of a new support to increase system stiffness. In this study, two braces with a band clamp are installed at the middle of the scrubber to raise its MNFs beyond the resonance region of concern, as displayed in Figure 8.

3.2. Resonance Analysis. The effectiveness of the vibration reduction treatment should be analysed before implementation. Finite element method (FEM) is also useful to 


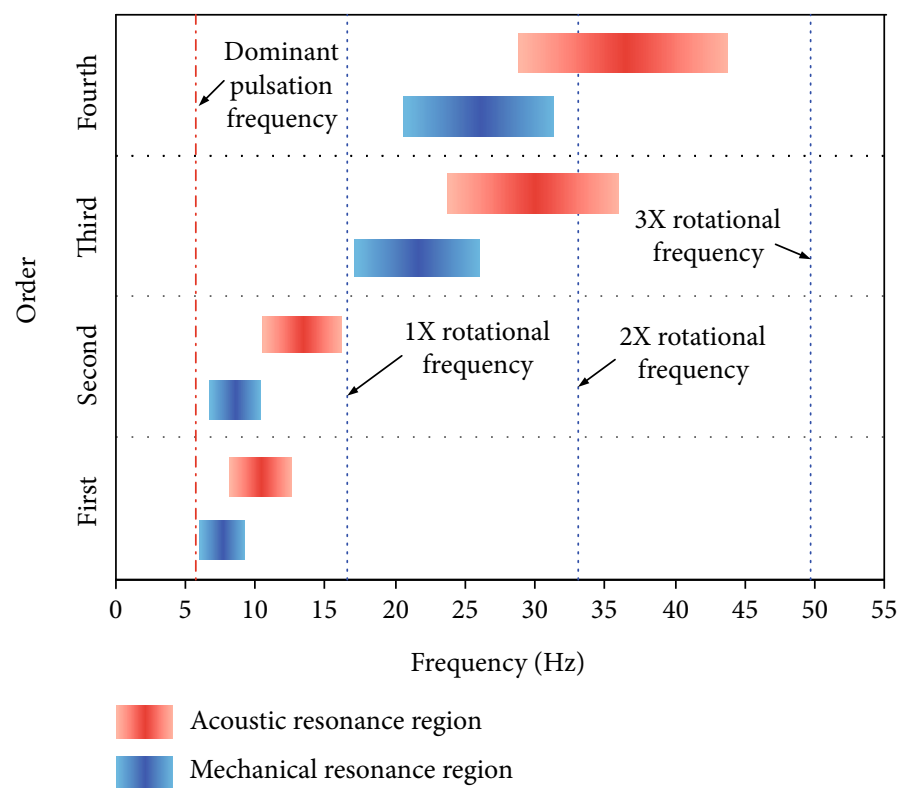

FIgURE 11: Resonance analysis of the modified model of the scrubber system.

determine modal parameters of a structure system. The simulation model of the original scrubber system modelled from the construction drawings and physical measurement was used to calculate the MNFs and mode shapes, which shall be validated by the results of modal experiment discussed in Section 2.3. Material of the scrubber system was steel with density $\rho=7850 \mathrm{~kg} / \mathrm{m}^{3}$, Young's modulus $E=210 \mathrm{GPa}$, and Poisson's ratio $v=0.3$. The scrubber inlet and outlet pipelines are restrained by several supports, as presented in Figure 1; each support can be simplified as a spring with three stiffness values of $k_{\mathrm{H}}, k_{\mathrm{V}}$, and $k_{\mathrm{A}}$, as shown in Figure 9. These stiffness values at locations S1, S2, and S3 (see Figure 1) can be calculated by FEM using the software Ansys, the results of which are listed in Table 7 [21].

Using these boundary conditions in Table 7, the first mechanical natural frequency of the original scrubber system is $6.21 \mathrm{~Hz}$. There is a relatively low (4\%) disagreement compared with the result of modal experiment. Such a slight disagreement is acceptable in engineering application, so the simulation model of the original scrubber system was validated and then was used to optimize the design of the two braces. Some factors causing the disagreement could be idealizations and simplifications of the scrubber structure, difficulties in obtaining actual stiffness of support because of insufficient support, uncertainties in surface soil effect on concrete piers, etc.

A modified model of the scrubber system was modelled on the basis of the vibration reduction treatment shown in Figure 8, in which MNFs greatly depend on the stiffness of the two braces. The brace can be defined as a spring with different axial and radial stiffness. Since the two braces and band clamp are connected together by several bolted connections, the axial stiffness of the brace has far greater influence on the MNFs of the modified model than its radial stiffness. From Figure 10, the first MNF of the modified model increases with an increase in the axial stiffness of brace and increases greatly

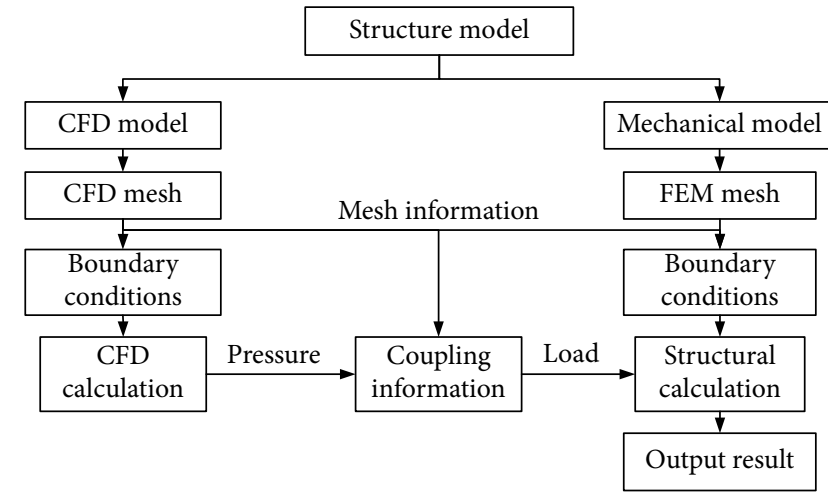

Figure 12: One-way FSI analysis process for flow-induced vibration.

from $1 E+04 \mathrm{~N} / \mathrm{mm}$ to $1 E+06 \mathrm{~N} / \mathrm{mm}$. To control the vibration problem, the predicted MNFs of the modified model should be designed to be separated from the dominant excitation frequencies of $5.9 \mathrm{~Hz}$ by at least $20 \%$, which means the axial stiffness of the brace should be at least $1.06 E+05$ $\mathrm{N} / \mathrm{mm}$ to ensure the modified model has a mechanical natural frequency higher than $7.08 \mathrm{~Hz}$.

In order to avoid mechanical resonance and acoustic resonance, the MNFs and acoustic frequencies of the modified scrubber system should have a separation margin of $20 \%$ from the significant excitation frequencies, such as dominant pulsation frequency and the $1 \mathrm{X}$ (first) rotational frequency of the reciprocating compressor. In this study, the first four MNFs of the modified model were obtained by the finite element method with the assumption that the axial stiffness of the brace was $2 E+05 \mathrm{~N} / \mathrm{mm}$. Resonance analysis was performed to show the relationships among the MNFs, acoustic frequencies, dominant pulsation frequency, and rotational frequencies of the modified model. As show in Figure 11, the blue boxes present the first four mechanical resonance 


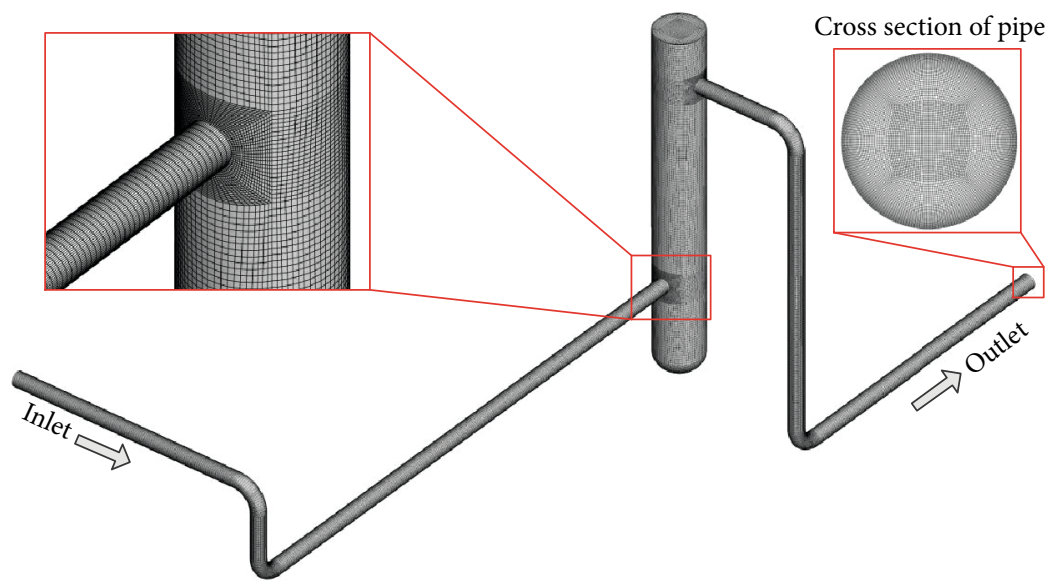

Figure 13: Numerical mesh of the CFD model in the modified scrubber system.

regions, and the red boxes the first four acoustic resonance regions; the dominant pulsation frequency, $1 \mathrm{X}$ rotational frequency, and $3 \mathrm{X}$ rotational frequency are beyond the resonance region; the $2 \mathrm{X}$ rotational frequency is within the thirdand fourth-order acoustic resonance regions, but not in the core region. As the first-order acoustic frequency excited by the dominant excitation frequency is often more destructive than others in engineering application, it can be seen that both mechanical resonance and acoustic resonance are avoided by this vibration reduction treatment.

3.3. Fluid-Structure Interaction Vibration Analysis. The vibration of the scrubber system is a complex fluidstructure interaction (FSI) problem, the fluid flow exerts pressure loads on the structure, and these pressure loads induce structural deformation and vibration to change the fluid flow itself. Such problems generally need numerical simulations, as it is difficult to obtain analytical solutions. From Table 3, the maximum vibration displacement of the scrubber system is 215.8 micron; it can be seen that such displacement is not large enough to have a significant impact on the fluid flow, so one-way coupling FSI analysis can be applicable for vibration simulation of the scrubber system. The one-way FSI analysis process is illustrated in Figure 12, which shows that the pressure calculated by CFD (Computational Fluid Dynamics) calculation at the fluid-structure interface is transferred to the mechanical model and applied as load in structural calculation.

To evaluate the vibration level of the modified scrubber system at its design condition, one-way FSI analysis was performed. The CFD model of the modified scrubber system was built up for CFD calculation. The numerical mesh of the CFD model is constructed with a combination of unstructured and structural mesh elements, as plotted in Figure 13. Since the results of CFD calculation are very sensitive to the mesh quality, this numerical mesh independence was tested, which showed that a deviation of less than $0.1 \%$ was obtained in relation to pressure drop.

The design condition of the scrubber is the processing capacity which is $166 \times 10^{4} \mathrm{Nm}^{3} / \mathrm{d}$, the outlet pressure $30 \mathrm{MPa}$, and the rotational frequency $16.667 \mathrm{~Hz}(1000 \mathrm{rpm})$. According to the API 618 standards, the maximum allowable
TABLE 8: Boundary conditions of the CFD model in the scrubber system for CFD calculation.

\begin{tabular}{lcc}
\hline Position & Boundary condition & Value \\
\hline Inlet & Velocity inlet & $4.215(\mathrm{~m} / \mathrm{s})$ \\
Outlet & Pressure outlet & $30+0.075 \sin (104.667 t)(\mathrm{MPa})$ \\
Wall & Wall & No slip wall \\
\hline
\end{tabular}

pressure pulsation is $0.5 \%$, and the static pressure of gas is $30 \mathrm{MPa}$, so the dynamic pressure calculated is $0.15 \mathrm{MPa}$ [22]. Hence, the pressure at the end of the scrubber outlet pipeline can be described as $p=30+0.075 \sin (104.667 t)$ (MPa); the boundary conditions for CFD calculation are listed in Table 8. In this paper, transient-state CFD calculation was carried out using the software FLUENT, the realizable $k-\varepsilon$ model was employed, time step was $0.0001 \mathrm{~s}$, and total time is $0.06 \mathrm{~s}$. The pressure distribution of the fluidstructure interface in the CFD model at $0.04 \mathrm{~s}$ is presented in Figure 14.

According to the one-way FSI analysis process in Figure 12, these pressure loads were transferred to the mechanical model of the modified scrubber system, and then, the vibration response was simulated in structural calculation using the software Ansys. Figure 15 shows the vibration velocity of the modified scrubber system; the maximum velocity of $9.63 \mathrm{~mm} / \mathrm{s}$ observed at the top of the scrubber is below $18 \mathrm{~mm} / \mathrm{s}$, which illustrates that the vibration level is reduced to the allowable limit when operating at its design condition.

\section{Implementation and Evaluation of Countermeasures}

Both the resonance analysis and fluid-structure interaction vibration analysis indicate that the vibration reduction treatment proposed is effective to mitigate the vibration problem. Installation of two braces with a band clamp is implemented on the scrubber on the basis of the above analysis, as displayed in Figure 16. After modification of the scrubber system, vibration and pressure measurements were carried out at the same points as before. The operating parameters of 


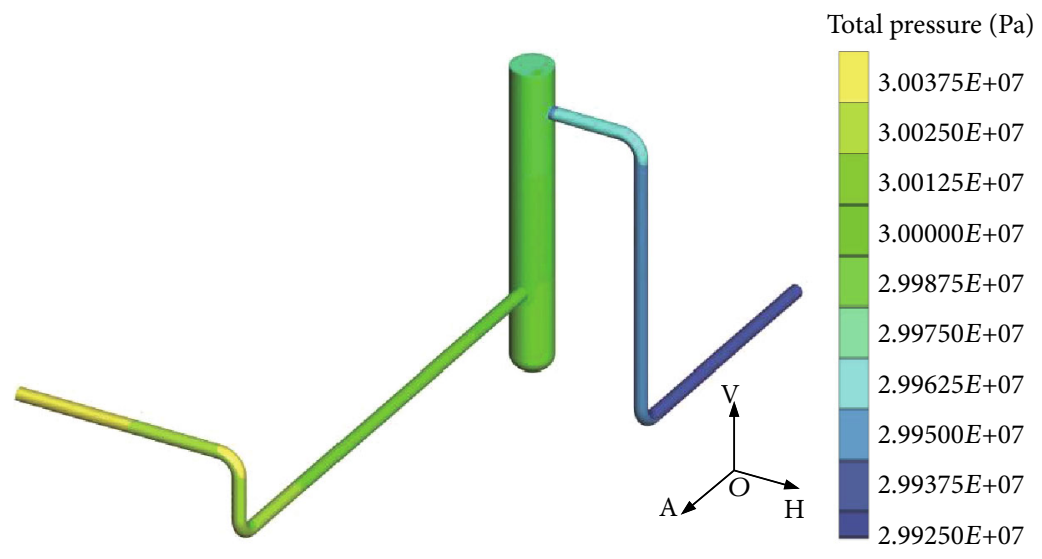

FIgURe 14: Pressure distribution of the fluid-structure interface in the CFD model at $0.04 \mathrm{~s}$.

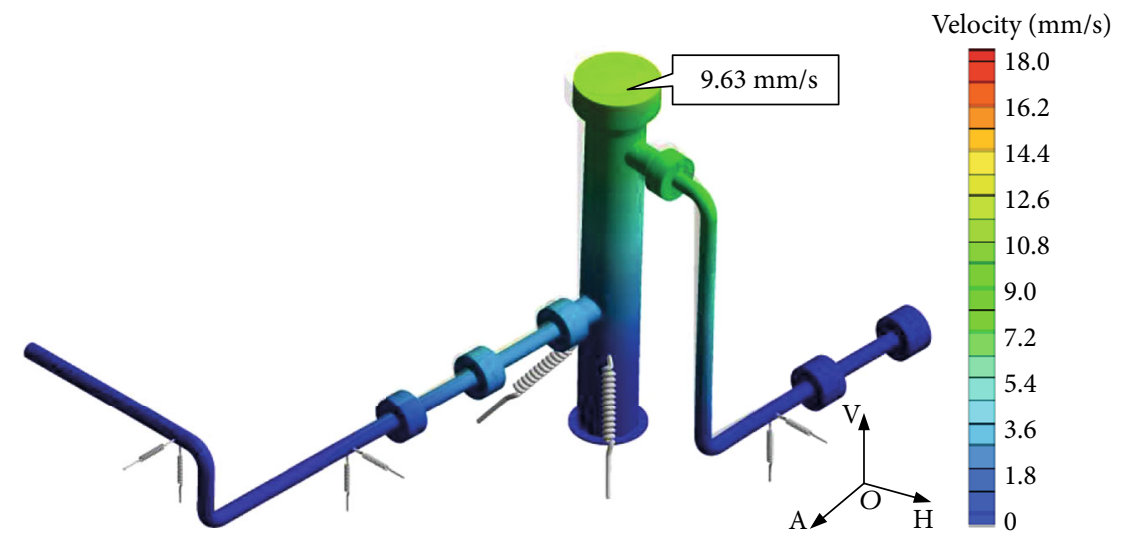

FIGURE 15: Vibration velocity of the modified scrubber system at its design condition.

the reciprocating compressor during measurements after modification are listed in Table 9, which are very similar to that (see Table 2) before. The comparison of vibration velocity measured at points V1, V2, and V3 before and after modification is plotted in Figure 17; it can be seen that all the vibration velocity values are reduced to a considerable extent; especially, the maximum vibration velocity at point $\mathrm{V} 2$ in the A direction is decreased by $67.31 \%$ from $25.76 \mathrm{~mm} / \mathrm{s}$ to $8.42 \mathrm{~mm} / \mathrm{s}$. The velocity spectrum of point V2 after modification, as shown in Figure 18, outlines that the dominant frequency of vibration is the compressor rotational frequency of $16.56 \mathrm{~Hz}$, but the vibration amplitudes occurring at $5.92 \mathrm{~Hz}$ are small. By comparing the pressure spectrum of point P2 before and after modification presented in Figure 19, the dominant frequency is $16.56 \mathrm{~Hz}$, and pressure pulsation occurring at $5.9 \mathrm{~Hz}$ declines by $84.4 \%$ from $0.122 \mathrm{MPa}$, peak to peak, to $0.019 \mathrm{MPa}$, peak to peak.

\section{Results and Discussion}

The potential causes of vibration can be revealed by vibration and pulsation measurements, acoustic analysis, and modal analysis. Vibration measurement and analysis are beneficial for diagnosis and characterization of vibration. Pulsation measurement is a good way of understanding the characteristics of pressure pulsation for pulsation reduction to control

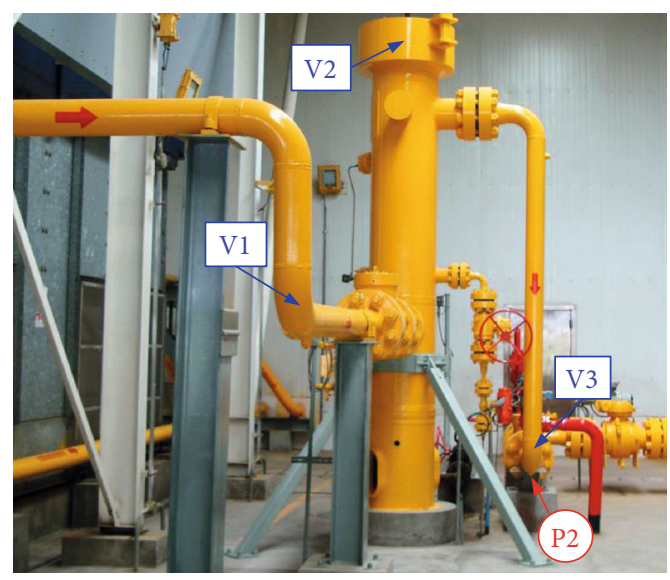

FIgURE 16: The modified scrubber system supported by two braces.

TABLE 9: The operating parameters of the reciprocating compressor after scrubber modification.

\begin{tabular}{lcccc}
\hline $\begin{array}{l}\text { Rotational } \\
\text { speed }(\mathrm{rpm})\end{array}$ & $\begin{array}{c}\text { Processing } \\
\text { capacity }\left(\mathrm{Nm}^{3} / \mathrm{d}\right)\end{array}$ & $\begin{array}{c}\text { Inlet } \\
\text { pressure } \\
(\mathrm{MPa})\end{array}$ & $\begin{array}{c}\text { Outlet pressure } \\
(\mathrm{MPa})\end{array}$ \\
\hline 994 & $145.8 \times 104$ & 7.56 & 13.32 & 24.26 \\
\hline
\end{tabular}




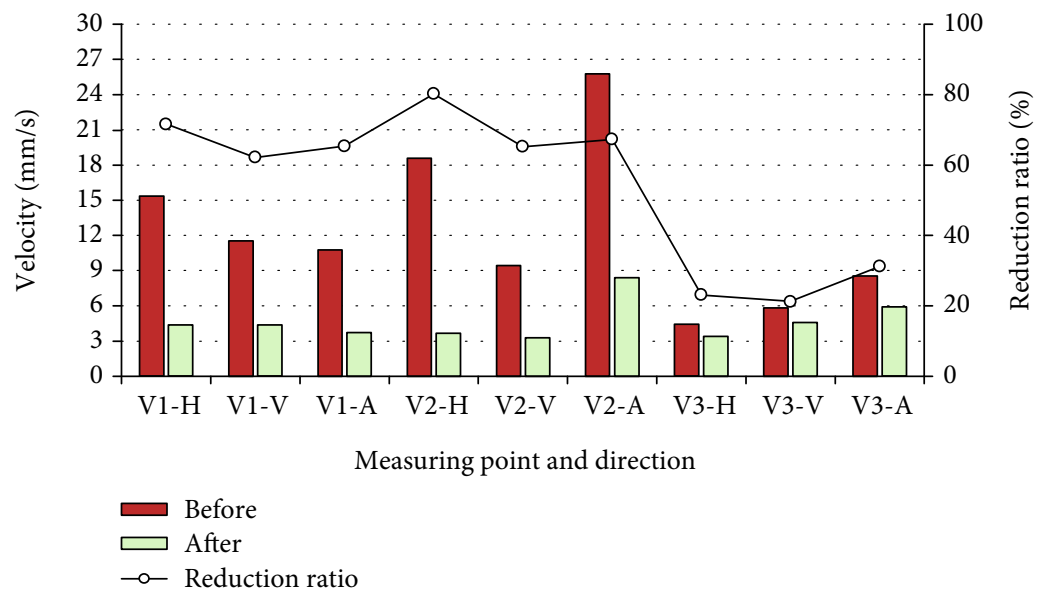

FIGURE 17: Comparison of vibration velocity measured before and after modification.

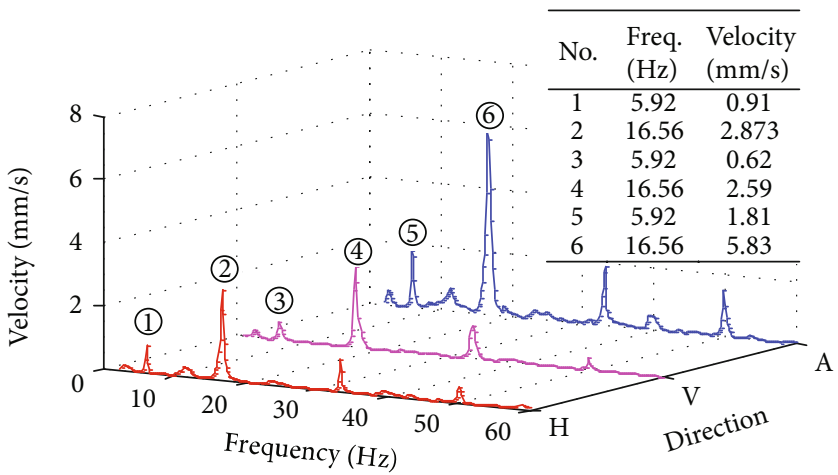

Figure 18: Velocity spectrum of point V2 after modification.

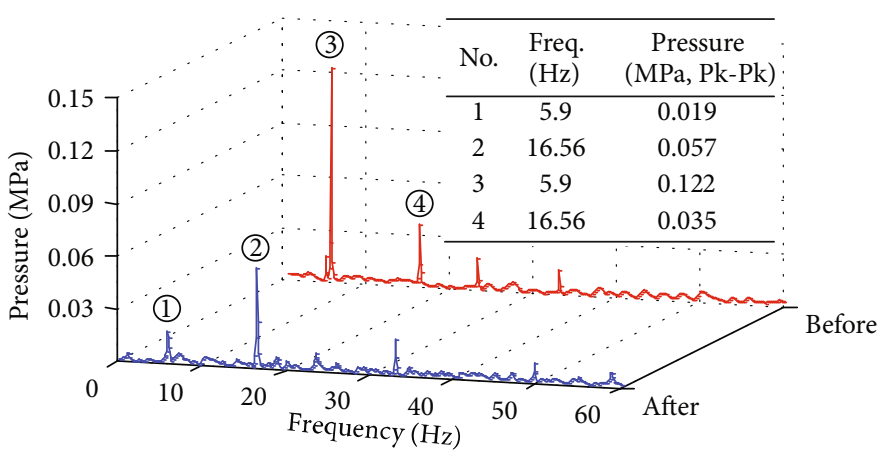

FIgURE 19: Pressure spectrum comparison of point P2 before and after modification.

flow-induced vibration. Acoustic analysis is used to determine the acoustic frequencies of system to avoid acoustic resonance. Modal analysis using experiment and/or the finite element method is used to obtain the modal parameters to avoid mechanical resonance. In this paper, the highest vibration of the scrubber system was observed near the mechanical resonance frequency of $5.94 \mathrm{~Hz}$, followed by $16.56 \mathrm{~Hz}$; the excitation source resulting from pressure pulsation in the scrubber had several clear spikes in the range of $0-70 \mathrm{~Hz}$, which clearly contained $5.9 \mathrm{~Hz}$ and $16.56 \mathrm{~Hz}$, so the excessive vibration problem resulted from pressure pulsation-induced mechanical resonance.
Effective vibration mitigation measures are needed to be developed based on field measurement data and structural dynamics models for optimizing feasible solutions. Flowinduced vibration can be mainly controlled by avoiding mechanical resonance, acoustic resonance, and high pressure pulsation in a structure system. Resonance analysis is essential for avoidance of mechanical resonance and acoustic resonance in system. FSI analysis using the finite element method can determine the vibration level of the structure system. However, the accuracy of results depends greatly on the idealizations and simplifications of system, the numerical mesh quality, boundary conditions, etc. In this study, a 
vibration reduction treatment was proposed by installation of two braces with a band clamp at the middle of the scrubber to increase its MNFs; the simulation model of the original scrubber system was developed and validated by comparison with the modal experiment, resonance analysis revealed mechanical resonance, and acoustic resonance can be avoided when the brace had an axial stiffness greater than 2 $E+05 \mathrm{~N} / \mathrm{mm}$, and the FSI vibration analysis revealed that the vibration level of the modified scrubber system at its design conditions was within the acceptable limit.

Two braces with band clamp were installed on the scrubber as countermeasure against vibration. The effectiveness of the vibration reduction treatment was confirmed by comparison with the field measured data before and after modifications. The MNFs of the modified scrubber increased and was away from the dominant excitation frequencies of pressure pulsation, so mechanical resonance was avoided. The vibration and pulsation values were reduced greatly after modification. To conclude, with this modification in the scrubber system, the vibration problem was eliminated altogether and the scrubber can operate safely at its design conditions.

\section{Conclusions}

Flow-induced vibration in a reciprocating compressor system can only be minimized with proper design and configuration of structure. There are two elastic vibration systems: mechanical structure system and acoustic system; each system has natural or resonant frequencies. Severe vibration can be induced by mechanical and/or acoustic resonance due to coincidence with a particular mechanical natural frequency and/or acoustic frequency. Field measurements including vibration, pressure pulsation, and modal experiment in combination with frequency spectrum analysis are useful to diagnose vibration problem. Development of a practical and effective vibration control measure should need field measured data, resonance analysis, and FSI vibration analysis using the finite element method.

\section{Data Availability}

The data used to support the findings of this study are available from the corresponding author upon request.

\section{Conflicts of Interest}

The authors declare that there is no conflict of interest regarding the publication of this paper.

\section{Acknowledgments}

This research was funded by the Open Research Subject of Key Laboratory (Research Base) of Fluid and Power Machinery of Xihua University, Ministry of Education (szjj2017081); the Key scientific research fund of Xihua University (Z17118); the Natural Science Foundation of the Education Department of Sichuan Province (18ZB0574).

\section{References}

[1] S.-H. Lee, S.-M. Ryu, and W.-B. Jeong, "Vibration analysis of compressor piping system with fluid pulsation," Journal of Mechanical Science and Technology, vol. 26, no. 12, pp. 3903-3909, 2012.

[2] Y. Li, K. Quan, R. Wu, Y. Chang, B. Guo, and B. Zhang, "Numerical simulation and experimental validation of large pressure pulsation in reciprocating compressor," Energy Procedia, vol. 160, pp. 606-613, 2019.

[3] H. Lu, X. Wu, and K. Huang, "Study on the effect of reciprocating pump pipeline system vibration on oil transportation stations," Energies, vol. 11, no. 1, p. 132, 2018.

[4] S. Li, B. W. Karney, and G. Liu, "FSI research in pipeline systems - a review of the literature," Journal of Fluids and Structures, vol. 57, pp. 277-297, 2015.

[5] M. Siba, W. Wanmahmood, M. Z. Nuawi, and R. Rasani, "Flow-induced vibration in pipes: challenges and solutions-a review," Journal of Engineering Science and Technology, vol. 11, no. 3, pp. 362-382, 2016.

[6] Y. Zhao, B. Zhao, Q. Zhou, X. Jia, J. Feng, and X. Peng, "Anal$y$ ysis and control of severe vibration of a screw compressor outlet piping system," in International Compressor Engineering Conference, Purdue University, 610 Purdue Mall, West Lafayette, Indiana, United States, 2016.

[7] T. C. Allison and J. Bennett, "Acoustically induced vibration mitigations in compressor piping systems," in Turbo Expo: Power for Land, Sea, and Air, no. article V009T024A023, 2016American Society of Mechanical Engineers, 2016.

[8] J. Wu and S. Y. Zheng, "Field measurement and numerical study of the vibration in the pipeline of centrifugal compressor," Journal of Pressure Vessel Technology, vol. 141, no. 5, 2019.

[9] P. Cyklis, "Advanced techniques for pressure pulsations modeling in volumetric compressor manifolds," Journal of vibration and acoustics, vol. 132, no. 6, 2010.

[10] J. Wang, C. Deng, S. Zhang, X. Guo, and G. Yang, "Research on vibration control in a reciprocating compressor piping system using an orifice tube structure," in 2019 2nd International Conference on Safety Produce Informatization (IICSPI), pp. 133-136, Chongqing, China, 2019, IEEE.

[11] P. Dubey, G. Reddy, and K. Vaze, "Vibration mitigation of H2s booster discharge pipeline of a typical heavy water plant," Procedia Engineering, vol. 86, pp. 818-826, 2014.

[12] T. Han, C. Huang, and A. C. Tan, "Experimental and finite element analysis to identify the source of vibration of a coach," Engineering Failure Analysis, vol. 44, pp. 100-109, 2014.

[13] F. Trebuňa, F. Šimčák, R. Huňady, and M. Pástor, "Identification of pipes damages on gas compressor stations by modal analysis methods," Engineering Failure Analysis, vol. 27, pp. 213-224, 2013.

[14] Q. Ma, Z. Wu, G. Yang, Y. Ming, and Z. Xu, "Pulsation suppression in a reciprocating compressor piping system using a two-tank element," Proceedings of the Institution of Mechanical Engineers, Part E: Journal of Process Mechanical Engineering, vol. 232, no. 4, pp. 427-437, 2017.

[15] M. H. Ghazali, L. M. Hee, and M. S. Leong, "Piping vibration due to pressure pulsations," in Advanced Materials Research, pp. 350-354, Trans Tech Publ, 2014.

[16] Y.-W. Kim and Y.-S. Lee, "Damage prevention design of the branch pipe under pressure pulsation transmitted from main 
steam header," Journal of Mechanical Science and Technology, vol. 22, no. 4, pp. 647-652, 2008.

[17] ISO, Mechanical vibration - measurement and evaluation of machine vibration - part 1: general guidelines, ISO, 2016.

[18] S. Li, L. Zhang, and C. Kong, "Vibration failure analysis and countermeasures of the inlet pipelines at a gas Compressor Station," Shock and Vibration, vol. 2019, 8 pages, 2019.

[19] Z. Liang, S. Li, J. Tian, L. Zhang, C. Feng, and L. Zhang, "Vibration cause analysis and elimination of reciprocating compressor inlet pipelines," Engineering Failure Analysis, vol. 48, pp. 272-282, 2015.

[20] T. Nakamura, S. Kaneko, F. Inada et al., Flow-Induced Vibrations: Classifications and Lessons from Practical Experiences, Butterworth-Heinemann, 2013.

[21] P. A. A. M. Junior and T. M. Portela, "Evaluation of the stiffness effect of pipe supports in relation to static and dynamic loads in a flexibility analysis," International Journal of Advanced Engineering Research and Science, vol. 5, no. 6, pp. 91-94, 2018.

[22] P. Shejal and A. Desai, "Pulsation and vibration study of reciprocating compressor according to API 618," International Journal of Modern Engineering Research, vol. 4, no. 7, 2014. 